\title{
A randomized controlled trial on the effect of incomplete milking during early lactation on ketonemia and body condition loss in Holstein dairy cows
}

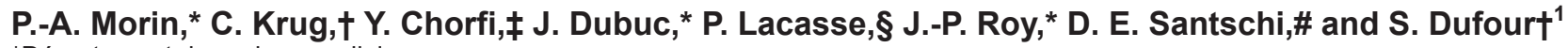 \\ *Département des sciences cliniques, \\ †Département de pathologie et de microbiologie, and \\ ‡Département de Biomédecine vétérinaire, Faculté de médecine vétérinaire, Université de Montréal, 3200 rue Sicotte, Saint-Hyacinthe, QC, \\ Canada, J2S 2M2 \\ §Sherbrooke research and development center, Agriculture and Agri-food Canada, 2000 College, Sherbrooke, QC, J1M 0C8, Canada \\ \#Valacta, Ste-Anne-de-Bellevue, QC, Canada, H9X 3R4
}

\begin{abstract}
Limiting milk production for a short period of time in early lactation could be a relevant strategy to prevent hyperketonemia (HYK). From December 2013 to March 2015, 838 multiparous Holstein cows from 13 herds were enrolled in a randomized controlled trial evaluating the effect of incomplete milking in early lactation on ketonemia and its effect on body condition score (BCS) loss. Cows were randomly assigned $4 \mathrm{wk}$ before expected calving date to 1 of 2 treatment groups, (1) a conventional milking protocol $(\mathrm{CON})$ for which cows were completely milked or (2) an incomplete milking protocol (INC) for which a maximum of 10 to $14 \mathrm{~kg}$ of milk/d were withdrawn during the first $5 \mathrm{~d}$ in milk (DIM). $\beta$-Hydroxybutyrate (BHB) concentrations were measured from blood samples collected on each cow 3 times at weekly intervals. Hyperketonemia was defined as $\mathrm{BHB} \geq 1.4 \mathrm{mmol} / \mathrm{L}$. Body condition score variation in the postcalving period was calculated by subtracting BCS assessed at wk 7 from BCS assessed at first week after calving. Effect of treatment on ketonemia and prevalence of HYK were evaluated for 4 specific time periods: 1 to 3,4 to 7, 8 to 17, and 18 to 26 DIM. Effect of treatment on ketonemia was investigated using linear mixed models with natural logarithm of BHB measurements as outcome and treatment groups as fixed effect. Generalized linear mixed models with HYK as outcome, using logit link, and treatment groups as fixed effect were used to investigate effect of treatment on odds of HYK. A logistic regression model with BCS loss $(<0.75$ or $\geq 0.75$ ) as outcome and treatment groups and herd as fixed effects was used to study effect of INC on odds
\end{abstract}

Received May 12, 2017.

Accepted January 9, 2018.

${ }^{1}$ Corresponding author: simon.dufour@umontreal.ca of having BCS loss $\geq 0.75$. A total of 813 lactations had complete data and were used for statistical analysis of ketonemia and HYK. A total of 709 lactations had complete data and were used for analysis of BCS loss. Geometric means of blood BHB concentrations during the 1 to 3,4 to 7,8 to 17 , and 18 to 26 DIM periods were, respectively, $0.72(95 \%$ confidence interval $=$ $0.66,0.80), 0.66(0.60,0.73), 0.90(0.80,1.01)$, and 0.93 $(0.83,1.05) \mathrm{mmol} / \mathrm{L}$ for INC, and $0.65(0.59,0.72)$, $0.79(0.72,0.87), 0.94(0.84,1.06)$, and $0.92(0.82$, $1.04) \mathrm{mmol} / \mathrm{L}$ for CON. Cows in INC group had lower ketonemia during the 4 to 7 DIM period. Predicted prevalence of HYK during the 1 to 3,4 to 7,8 to 17 , and 18 to 26 DIM periods were, respectively, 2.8 (3.2, 15.1), $4.6(2.0,10.0), 13.4(8.4,20.0)$, and $23.0 \%$ (17.4, 29.7) for INC and $2.6(2.5,13.8), 10.7(5.6,19.3), 19.4$ $(13.0,27.9)$, and $21.3 \%(16.0,27.8)$ for CON. The INC treatment reduced the prevalence of HYK during the 4 to 7 and 8 to 17 DIM periods. No association was observed between INC and BCS loss in the postcalving period. Overall, the incomplete milking protocol was effective for reducing ketonemia and prevalence of HYK during the early postpartum period.

Key words: dairy cow, ketosis, body condition score, incomplete milking, randomized controlled trial

\section{INTRODUCTION}

The peripartum transition period is generally defined as the interval from $3 \mathrm{wk}$ before to $3 \mathrm{wk}$ after calving (Wang et al., 2012). This period covers the end of pregnancy, parturition, and early lactation. Major hormonal, metabolic, and nutritional changes occur during this period while the animal aims to maintain homeostasis, to start lactogenesis, and to allow growth of the fetus and the cow itself (Bauman and Currie, 1980). In parallel to these changes, the cow's DMI increases from its nadir at calving to peak between wk 10 and 14 of lactation (NRC, 2001). Unfortunately, this peak of 
DMI is not synchronized with milk peak yield, which is usually observed between the fourth and eighth week of lactation (Keown et al., 1986). Because of the gap between DMI and milk peaks, an unavoidable period of negative energy balance (NEB) occurs (Holtenius et Holtenius, 1996). During NEB, carbohydrates are depleted quickly and cows have to use fat and protein reserves as source of energy (Tamminga et al., 1997; Herdt, 2000). This fat mobilization usually leads to ketone bodies production, an important source of energy for ruminants (Herdt, 2000). When excessive ketone bodies accumulate in blood, hyperketonemia (HYK) can occur and is associated with various health issues (Suthar et al., 2013; McArt et al., 2015). Thresholds of blood BHB values from $\geq 1.0$ to $\geq 1.4 \mathrm{mmol} / \mathrm{L}$ have been suggested to define HYK (Geishauser et al., 2000; Duffield et al., 2009; Ospina et al., 2010). Using milk BHB values, Santschi et al. (2016) showed that the overall prevalence of HYK in dairy herds in Quebec (Canada) was $22.6 \%$, with a higher prevalence for older cows (27.6\%). Using blood BHB values from 126 commercial dairy herds in Quebec (Canada), Dubuc and Denis-Robichaud (2017) observed a similar median herd prevalence (18\%) with important variation (range $=4.0-75.0 \%)$. Average cost per case of HYK was estimated at Can $\$ 203$ (Gohary et al., 2016) in Canada, $€ 257$ (Raboisson et al., 2015) in Europe, and \$289 (McArt et al., 2015) in the United States.

To modulate NEB, most research focused on optimizing energy input during the transition period. Nonetheless, it is also possible to improve energy balance by reducing energy output. The latter could be achieved by limiting the amount of milk harvested for a few days at the beginning of lactation. In a previous study, this was achieved by milking cows once a day during the first week of lactation (Loiselle et al., 2009). In another study, the volume of milk harvested was restricted during the first 5 DIM without altering milking frequency (Carbonneau et al., 2012). Whereas both strategies proved to be efficient for limiting NEB, milking cows once a day during the first week of lactation resulted in a reduction of $8.1 \%$ of the daily milk production over the first 13 wk of lactation compared with cows milked twice a day. This important milk yield reduction makes this approach less applicable in a commercial dairy context. When limiting milk extracted without altering milking frequency, however, no negative residual effect of treatment on subsequent milk production was observed (Carbonneau et al., 2012). The strategy proposed by Carbonneau et al. (2012) shows great potential but needs to be evaluated in a commercial farm environment. Therefore, the main objectives of our study were to evaluate the effect of an incomplete milking protocol (INC) on ketonemia and prevalence of HYK in early lactation. A secondary objective was to evaluate its effect on body condition loss from calving to milk peak; our hypotheses were that those NEB markers would be improved by the proposed strategy.

\section{MATERIALS AND METHODS}

A randomized controlled trial (RCT) was conducted to achieve study objectives. Research protocol was approved by Animal Ethics Committee of the Université de Montréal (13-Rech-1701). The reporting guidelines for Randomized Control Trials in Livestock and Food Safety statement (REFLECT) was used for planning the study and for preparing this manuscript (O'Connor et al., 2010).

\section{Participants}

A convenient sample of 13 commercial dairy herds located within $50 \mathrm{~km}$ of Saint-Hyacinthe (Quebec, Canada) were selected for this RCT. To be eligible, dairy producers had to (1) milk multiparous cows ( $\geq 2$ nd lactation) as indicated by the research team following the randomization process; (2) record specific health events occurring on enrolled cows (dystocia, clinical hypocalcemia, and retained placenta) ; (3) allow minimally invasive sampling on their animals by the research team such as venipuncture of coccygeal vessels; (4) share DHI records with the research team; and (50 manually or electronically record milk production of each enrolled cow at least twice a week for the first $3 \mathrm{wk}$ of lactation. Results from ketonemia measurements were made available to dairy producers, as many of them already used these measurements as part of their monitoring program. No recommendation was made, however, regarding the decision to treat an animal, the treatment, or for modifying the general farm management.

\section{Sample Size Estimation}

Sample size calculations were conducted a priori for each of the outcomes studied in this RCT using the POWER procedure of the SAS 9.4 software (SAS Institute Inc., Cary, NC). The outcome requiring the largest sample size was odds of HYK. Assuming a prevalence of HYK of $12 \%$ in the CON group (Chapinal et al., 2011) and of $6 \%$ in the INC group (Carbonneau et al., 2012), a type I error rate of 0.05 , and using a 2-tail Fisher's exact test (Fisher, 1935), we estimated that a sample size of 386 animals per treatment group was required to achieve a power of $90 \%$. As these calculations did not 
consider clustering of measurements by cows and herds, we aimed for 400 cows per group to hopefully achieve a study power $>80 \%$.

\section{Intervention}

The INC treatment consisted of extracting no more than $10 \mathrm{~kg}$ of milk/d on DIM 1 to $3,12 \mathrm{~kg}$ of milk/d on DIM 4 , and $14 \mathrm{~kg}$ of milk/d on DIM 5 without altering the milking frequency used on farm. This procedure was a modified version of that applied by Carbonneau et al. (2012), where $6,8,10,12$, and $14 \mathrm{~L}$ of milk were withdrawn, respectively, on DIM 1, 2, 3, 4, and 5 postpartum. This modification was made to facilitate the implementation of INC by milking employees on commercial dairies. Milk weights were estimated based on milking unit measurement or were read from a transparent graduated milking jar. For comparison, a group of cows conventionally milked (CON) was followed. Cows in this group were milked until milking unit was automatically removed based on usual farm procedures. Milking cows incompletely, similarly to INC cows, was part of the conventional milking routine of 6 herds for the first and second milkings after calving.

Treatment implementation was performed by dairy producers or trained employees. Depending on the herds, the number of employees involved in treatment implementation ranged from 1 to 8 . The research team visited each farm once a week to enroll and allocate cows to treatment group $4 \mathrm{wk}$ before the expected calving date and to sample cows already enrolled.

\section{Treatment Allocation}

For each herd, a list of expected calving dates was obtained and multiparous cows were allocated to CON or INC groups using series of random numbers generated with the ALEA function of the Excel 2013 software (Microsoft, Redmond, WA). Approximately 3 to $4 \mathrm{wk}$ before the expected calving date, cows in the INC group were identified with a colored leg band. As dairy producers had to apply treatment, they were not blinded to treatment allocation. Similarly, members of the team could not be blinded to group allocation when collecting samples on recruited cows.

\section{Milk Production and Composition Data}

In 6 of the 13 participating farms, daily milk production was recorded by the milking system software from which they were directly retrieved. In the remaining herds, daily milk production was manually recorded by producers at least once a week for the first month of lactation and through monthly DHIA testing.

\section{Outcomes and Effect Modifiers}

Two primary outcomes and one secondary outcome were investigated to describe the effect of treatment on NEB: ketonemia, prevalence of HYK, and BCS loss in early lactation.

Ketonemia and HYK. Cows were sampled for blood BHB measurement once a week during the first $3 \mathrm{wk}$ in milk beginning at least $36 \mathrm{~h}$ after calving. A red-top 10-mL BD vacutainer (Becton, Dickinson and Company, Franklin Lakes, NJ) was filled using venipuncture of the coccygeal vessels and immediately analyzed on farm with a Precision Xtra hand-held device (Abbott Diabetes Care, Alameda, CA). Cows presenting blood $\mathrm{BHB}$ values $\geq 1.4 \mathrm{mmol} / \mathrm{L}$ were considered to have HYK (Duffield et al., 2009; Iwersen et al., 2009).

Variation in BCS in Early Lactation. Body condition scores (Wildman et al., 1982) were assessed for each cow at different time points by 3 members of the research team: 2 veterinarians and 1 trained animal health technician. The 5-category BCS scale was used with subcategories with 0.25 increments between the second and fourth categories: emaciated (1), thin (2), average (3), fat (4), to obese (5; Ferguson et al., 1994). Time points for BCS assessments were (1) 3 to $4 \mathrm{wk}$ before expected calving date, (2) during the first week postpartum, and (3) during the seventh week in milk. Body condition score variation in the postcalving period ( $\triangle$ BCS ) was computed by subtracting BCS assessed at the seventh week postpartum from BCS assessed at first week postpartum. It was divided in 2 categories: losses $\geq 0.75$ or $<0.75$ points.

Periods of Interest. Based on Carbonneau et al. (2012) and McArt et al. (2012), DIM at sampling were divided into 4 categories of importance: 1 to 3,4 to 7, 8 to 17 , and 18 to 26 DIM. Effects of treatment on ketonemia and HYK were studied independently for each of these periods.

Potential Measure of Effect Modifiers. Putative effect modifiers were investigated to identify specific cow characteristics that could improve the effect of the INC (Dohoo et al., 2009b). As potential variables that could modify the effect of the milking protocol on ketonemia, HYK, and $\triangle \mathrm{BCS}$, we considered precalving BCS, parity, dry period length, previous lactation relative milk, fat, and protein production, use of a monensin controlled release capsule (CRC; Elanco, Guelph, ON, Canada), health issues occurring in early lactation, and, finally, the herd itself (e.g., herd and feed management). Body condition score in the precalving period was dichotomized as $<3.75$ or $\geq 3.75$ (Pedron et al., 1993). Because a certain amount of energy is still needed for growth in second-lactation cows, parity was dichotomized into parity 2 and parity $\geq 3$. Dry period 
length was divided into 3 categories: short $(\leq 45 \mathrm{~d})$, usual (46-64 d) and long ( $\geq 65 \mathrm{~d}$ ). Previous lactation relative milk, fat, and protein production were represented using breed class average for milk (BCAM), fat (BCAF), and protein (BCAP), respectively. Breed class average for milk, fat, and protein, are indexes used by milk recording programs across Canada to compare milk, fat, and protein production of cows from different breeds, ages, and calving seasons. These 3 variables were divided in 2 categories: low to average $(<250)$ and high $(\geq 250)$. Cows receiving a CRC were compared with those not receiving such a device. Health events investigated for their potential role as measure of effect modifier were dystocia, clinical hypocalcemia, and retained fetal membranes. Dystocia was defined, as suggested by Djemali et al. (1987), as a calving necessitating 1 of these criteria: pull with 2 people, use of the fetal extractor, or veterinary procedures. Clinical hypocalcemia was defined, as proposed by Horst et al. (1997), as the incapacity of a cow to rise within $36 \mathrm{~h}$ after calving and resolved with calcium administration. Finally, retained placenta was defined, as suggested by Stevenson and Call (1988), as retention of fetal membranes more than $24 \mathrm{~h}$ after calving.

\section{Statistical Analyses}

Three statistical models were computed: (1) a linear mixed model to evaluate effect of treatment (INC or $\mathrm{CON}$ ) on ketonemia; (2) a generalized linear mixed model, using a logit link, to estimate the effect of treatment on odds of HYK; and (3) a logistic model to estimate the effect of treatment on odds of having a loss of BCS $\geq 0.75$ point. An $\alpha$ threshold of 0.05 was used to conclude on significance.

Ketonemia. Due to lack of normality, blood BHB values were transformed using the natural logarithm transformation. Linear mixed models were computed with the MIXED procedure of the SAS software (version 9.4, SAS Institute Inc.) for each period of interest to quantify the effect of treatment on the natural logarithm of blood BHB. With the sampling scheme used, a maximum of 1 ketonemia observation per cow was available during the 1 to 3,4 to 7 , and 18 to 26 DIM periods. For the 8 to 17 DIM period, cows could have 2 ketonemia measurements. For this reason, cow and herd random intercepts were used for this period to account for clustering of observation by cows and herds. Only a herd random intercept was used for the 1 to 3 , 4 to 7 , and 18 to 26 DIM models. General model used for the 8 to 17 DIM period is presented at Equation 1. For the 3 other periods, the cow random intercept was removed from Equation 1:

$$
\begin{aligned}
\ln (\mathrm{BHB})_{\mathrm{ijk}}= & \beta_{0}+\beta_{1} \text { Treatment }_{\mathrm{jk}}+\mathrm{v}_{0 \mathrm{k}} \\
& +\mathrm{u}_{0 \mathrm{jk}}+\mathrm{e}_{0 \mathrm{ijk}},
\end{aligned}
$$

where $\ln (\mathrm{BHB})$ is the predicted natural logarithm of blood BHB for the ith ketonemia measure of the jth cow from the kth herd; $\beta_{0}$ is the intercept; $\beta_{1}$ is the regression coefficient for treatment group; $\mathrm{v}_{0 \mathrm{k}}$ is the herd random intercept; $\mathrm{u}_{0 \mathrm{jk}}$ is the cow random intercept; and $\mathrm{e}_{0 \mathrm{ijk}}$ is the measurement error term. These last 3 terms are assumed to follow approximately normal distributions with homogeneous variance.

Statistical models were built following two steps. (1) For each period, models were computed with only treatment as predictor; and, (2) for each of potential effect modifiers previously described, effect modification was evaluated by adding 1 effect modifier variable and a treatment by effect modifier interaction term to the model presented in Equation 1. Effect modifier variables were retained when the interaction term yielded a $P$-value $<0.05$ to the $F$-test (Dohoo et al., 2009d). Potential effect modifiers were tested one by one to simplify interpretation. Regarding effect modification by herd, a random herd slope was added to Equation 1 (Dohoo et al., 2009c). As significance of a random slope cannot be formally tested, regression lines representing the effect of treatment on blood BHB natural logarithm were plotted for each herd for a random intercept only model and for a random intercept and random slope model. This allowed visual comparison of the models to evaluate whether effect of treatment was similar among herds.

In linear regression, when the natural logarithm transformation is used, estimates and 95\% CI can be back-transformed, but results are then interpreted on a multiplicative scale (i.e., BHB are multiplied by a factor of $\mathrm{x}$ for every 1 unit increase of the predictor) rather than on an additive scale (i.e., BHB increases by $\mathrm{x}$ for every 1 unit increase of the predictor; Dohoo et al., 2009b). Estimates and 95\% CI obtained were, therefore, back transformed and interpreted on the multiplicative scale.

Assumption of homoscedasticity was evaluated visually using the plot of standardized residuals against predicted values, and assumption of normality of residuals was evaluated using the $\mathrm{Q}-\mathrm{Q}$ plot. Because all variable tested were categorical, assumption of linearity was not investigated. Observations with leverage $\geq 0.005$ or Cook's distance $\geq 1.0$ were investigated to detect patterns of observations not well explained by the models or having important influence (Cook et Weisberg, 1982; Dohoo et al., 2009b)

$\boldsymbol{H} \boldsymbol{Y} \boldsymbol{K}$. A generalized linear mixed model using a logit link was computed with the GLIMMIX procedure 
of the SAS software (version 9.4, SAS Institute Inc.) for each of the 4 DIM periods to evaluate effect of milking protocols on odds of HYK. Structure of the model for each period was similar to the ketonemia model (Equation 1), with clustering of observations by cows and herds for the 8 to 17 DIM period and by herds for the 1 to 3,4 to 7 , and 18 to 26 DIM periods. The model used was

$$
\begin{gathered}
\mathrm{Y}_{\mathrm{ijk}} \sim \operatorname{Bernoulli}\left(\mathrm{P}_{\mathrm{ijk}}\right), \\
\operatorname{Logit}\left(\mathrm{P}_{\mathrm{ijk}}\right)=\beta_{0}+\beta_{1} \operatorname{Treatment}_{\mathrm{jk}}+\mathrm{v}_{0 \mathrm{k}}+\mathrm{u}_{0 \mathrm{jk}}, \\
\operatorname{Var}\left(\mathrm{Y}_{\mathrm{ij}} \mid \mathrm{P}_{\mathrm{ijk}}\right)=\mathrm{P}_{\mathrm{ijk}}\left(1-\mathrm{P}_{\mathrm{ijk}}\right),
\end{gathered}
$$

where $Y_{i j k}$ is a Bernouilli variable indicating whether the ith blood sample of the jth cow from the kth herd yielded blood $\mathrm{BHB} \geq 1.4 \mathrm{mmol} / \mathrm{L}$, and this event is observed with probability $\mathrm{P}_{\mathrm{ijk}}$; this probability is function of $\beta_{0}$, the intercept, and of $\beta_{1}$, the regression coefficient for treatment group; $\mathrm{v}_{0 \mathrm{k}}$ is the herd random intercept; and $\mathrm{u}_{0 \mathrm{jk}}$ is the cow random intercept. These last 2 terms are assumed to follow approximately normal distributions with homogeneous variance. Model construction was conducted similarly to ketonemia models. To facilitate interpretation, estimates were also transformed on a probabilistic scale using the invert logit function. If significant, interaction terms were presented using the layout proposed by Knol and VanderWeele (2012), and relative excess risk due to interaction was computed as described by Knol et al. (2007), with 95\% CI estimated using bootstrapping. Model assumptions were assessed as described for ketonemia models.

Body Condition Loss in the Postpartum Period. For this analysis, only 1 observation per cow was available and, therefore, observations were only clustered by herds. However, due to an estimation problem, a generalized mixed model with a herd random intercept could not be used to fit this model. Instead, herd was treated as a fixed effect and a conventional logistic model was used with the LOGISTIC procedure of the SAS software (version 9.4, SAS Institute Inc.) to evaluate effect of the milking protocol on odds of $\Delta \mathrm{BCS} \geq 0.75$ point in early lactation. The model was

$$
\begin{gathered}
\mathrm{Y}_{\mathrm{i}} \sim \operatorname{Bernoulli}\left(\mathrm{P}_{\mathrm{i}}\right) \\
\operatorname{Logit}\left(\mathrm{P}_{\mathrm{i}}\right)=\beta_{0}+\beta_{1} \operatorname{Treatment}_{\mathrm{i}}+\beta_{2} \operatorname{Herd}_{\mathrm{i}} \\
\operatorname{Var}\left(\mathrm{Y}_{\mathrm{i}} \mid \mathrm{P}_{\mathrm{i}}\right)=\mathrm{P}_{\mathrm{i}}\left(1-\mathrm{P}_{\mathrm{i}}\right)
\end{gathered}
$$

where $Y_{i}$ is a Bernoulli variable indicating whether the ith cow experienced a loss of $\mathrm{BCS} \geq 0.75$, and this event is observed with probability $\mathrm{P}_{\mathrm{i}}$; this probability is function of the intercept $\left(\beta_{0}\right)$, the regression coefficient for treatment group $\left(\beta_{1}\right)$, and of the herd effect $\left(\beta_{2}\right)$. Due to the low number of cows experiencing $\triangle \mathrm{BCS} \geq 0.75$ point, effect modification of treatment- $\triangle \mathrm{BCS}$ relationship by other variables was not investigated to avoid complete data separation. Model assumptions were assessed as described for other models.

\section{RESULTS}

\section{Descriptive Statistics}

Flow of Animals. Of the 13 herds enrolled, 9 used freestalls housing and 4 used tiestalls. Number of lactating cows per herd ranged from 35 to 250 . One farm used milking robots, 5 used rotary parlors, 3 used parallel parlors, and all tiestall herds used mobile milking units. Eleven farms fed a TMR, 1 a partially mixed ration, and 1 a component feeding ration. Only 1 herd milked fresh cows 3 times per day; all other herds, including the herd using a milking robot, milked fresh cows twice a day. From December 2013 through March 2015, 838 mature cows were enrolled in these herds for a total of 846 lactations ( 8 cows calved twice and started 2 different lactations during the RCT). Twentyfour lactations were not enrolled because cows calved before the randomization $(\mathrm{n}=10)$ or because producers applied the wrong milking protocol $(\mathrm{n}=14)$. Four cows allocated to INC group had less than $5 \mathrm{~d}$ on INC; these were still considered as having completed INC (i.e., intention to treat analysis) because those types of deviations are likely to occur in routine practice and should be included to correctly estimate effect of treatments (Hollis et Campbell, 1999).

Daily milk weight for the first 14 DIM for INC and CON cows are presented in Figure 1. On the first DIM, limiting milk output in INC cows to a maximum of $10 \mathrm{~kg} / \mathrm{d}$ had little effect on their actual production, as most cows in the CON group also produced less than 10 $\mathrm{kg} / \mathrm{d}$. However, between DIM 2 and 5 , cows in the CON group produced between 2.0 and 2.5 times more milk per day than the maximum output allowed in the INC group. On DIM 6, when the incomplete milking protocol was ended, cows from the INC group increased their daily milk production to a level close to that of $\mathrm{CON}$ cows (mean milk production of $31.0 \mathrm{~kg} / \mathrm{d}$ in INC cows on DIM 6 compared with $33.1 \mathrm{~kg} / \mathrm{d}$ in CON cows). On DIM 14, difference in production between groups were relatively small (mean milk production of 38.7 $\mathrm{kg} / \mathrm{d}$ in INC cows on DIM 14 compared with $39.8 \mathrm{~kg} / \mathrm{d}$ in CON cows). Difference in daily milk yield between groups at DIM 14 were not statistically significant $(P$ 


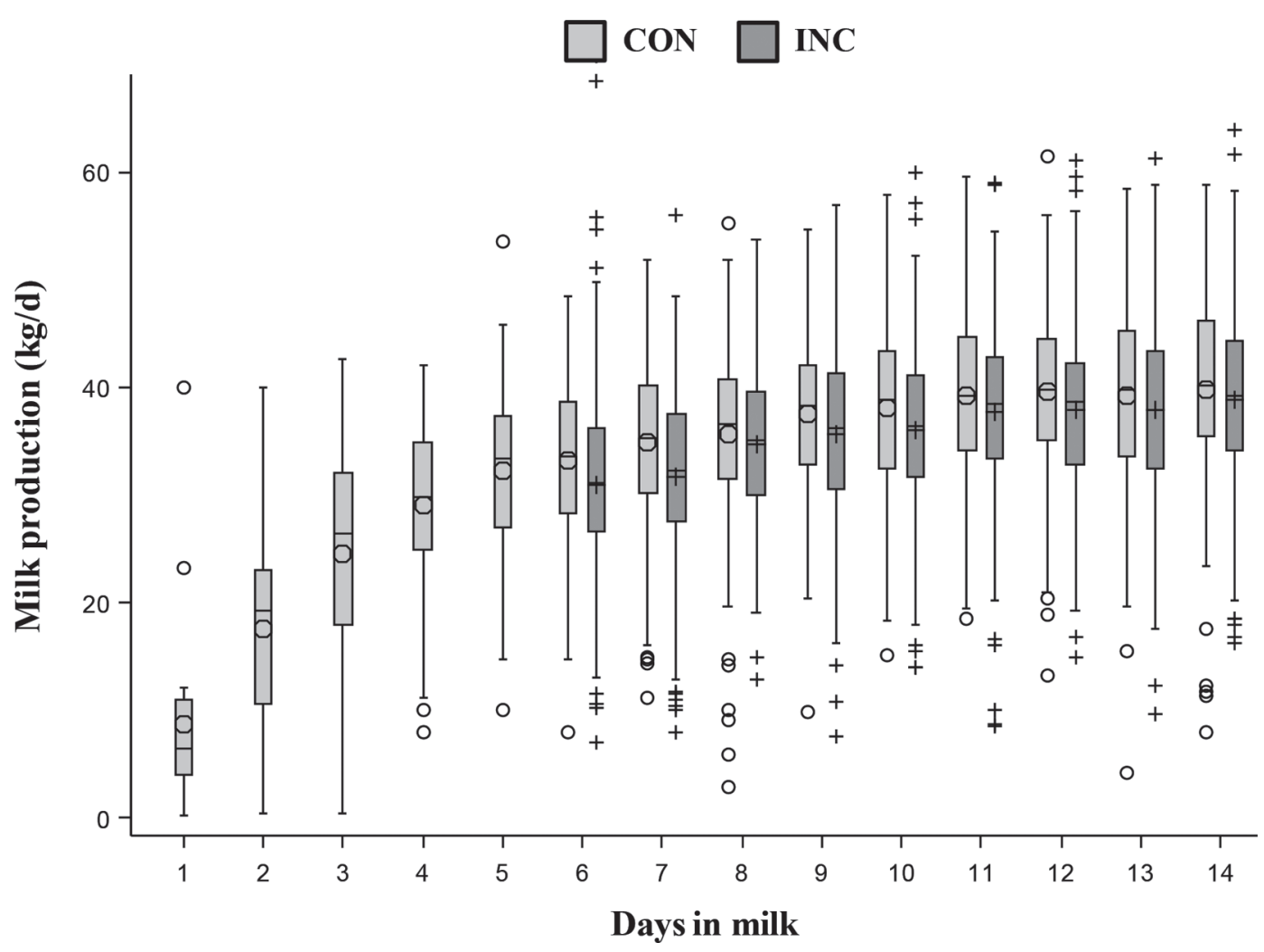

Figure 1. Boxplot of milk weight per day as function of milking protocols and DIM. Data obtained from 813 multiparous Holstein cow lactations from 13 herds participating in a randomized controlled trial evaluating the effect of an incomplete milking protocol (INC) during the first 5 DIM compared with a conventional milking protocol $(\mathrm{CON})$. The sign $(\mathrm{O}$ or +$)$ and line inside the box indicate, respectively, the mean and median milk production. Whiskers are drawn from the box to the most extreme point that is less than or equal to 1.5 times the interquartile range. Observations outside the values delimited by the whiskers are represented by individual markers.

$=0.43$ using a mixed linear regression model with a herd intercept).

Measure of Effect Modifiers. Minimum, median, and maximum values for BCS precalving were, respectively, 2.25, 3.5, and 4.5. Following categorization of effect modifiers as described in the Materials and Methods section, number of lactations with precalving BCS $\geq 3.75$ points was 234 (CON: 110 and INC: 124 ), whereas 538 (CON: 274 and INC: 264) had precalving BCS $<3.75$ points; 41 lactations (CON: 28 and INC: 13) had missing values because the BCS measurement was not collected by the research team. Minimum, median, and maximum values for parity were, respectively, 2, 3, and 11. There were 343 (CON: 175 and INC: 168) cows of second lactation and $470(\mathrm{CON}: 237$ and INC: 233) $\geq 3$ lactations. Minimum, median, and maximum number of days for dry period were, respectively, 7, 54, and $212 \mathrm{~d}$. We observed 117 (CON: 55 and INC: $62)$ short dry periods, 286 (CON: 157 and INC: 129) normal dry periods, 110 (CON: 58 and INC: 52) long dry periods, and 300 (CON: 142 and INC: 158) missing values because the exact dry off date was missing from herds records. Minimum, median, and maximum values for BCAM were, respectively, 118, 239, and 381. We observed 289 (CON: 145 and INC: 144) lactations with low to normal BCAM, 203 (CON: 97 and INC: 106) with high BCAM, and 321 (CON: 170 and INC: 151) missing values because data were missing from the DHI records. Minimum, median, and maximum values for BCAF were, respectively, 115, 249, and 393. We observed 239 (CON: 121 and INC: 118) lactations with low to normal BCAF, 244 (CON: 119 and INC: 125) with high, and 330 (CON: 172 and INC: 158) missing values because data were missing from the DHI records. Minimum, median, and maximum values for BCAP were, respectively, 116, 240, and 363 . We observed 277 (CON: 138 and INC: 139) lactations with low to normal BCAP, 206 (CON: 102 and INC: 104) with high BCAP, and 330 (CON: 172 and INC: 158) missing values because data were missing from the DHI records. There were 359 cow lactations receiving CRC prior calving (CON: 191 and INC: 168). In 10 out of 13 herds, CRC were administered systematically to multiparous cows. Among herds enrolled, 2 of 13 gave 
no monensin supplementation and 5 of 13 fed monensin as premix. Regarding health events, only 3 cows in INC (0 in CON) had dystocia for an incidence of $0.4 \%, 17$ cows suffered from clinical hypocalcemia after calving for a cumulative incidence of $2 \%$ (10 in CON and 7 in INC), and 29 experienced retained fetal membranes for a cumulative incidence of $4 \%$ (12 in CON and 17 in INC).

\section{Statistical Analyses}

Ketonemia. Ketonemia measurements were missing for 9 lactations because of errors from the research team ( $\mathrm{n}=6$ lactations) or because cows were culled before first sample ( $\mathrm{n}=3$ lactations). A total of 412 lactations were analyzed for CON, whereas 401 lactations were included in INC for blood BHB and HYK modeling. During the 8 to 17 DIM period, 333 cows had 2 blood BHB observations available for analysis, whereas only 1 observation was available for 462 cows during that period.

Blood BHB distributions categorized by milking protocol and DIM periods, are illustrated in Figure 2. Distributions of ketonemia values were right skewed for all DIM periods. Distributions were approximately normal after natural logarithm transformation. Estimates of linear mixed models evaluating effect of treatments on natural logarithm of BHB are presented in Table 1, whereas $\mathrm{BHB}$ geometric means estimates and $\mathrm{BHB}$ ratio between groups showing this association on the multiplicative scale are presented in Table 2. No difference was observed between groups during the 1 to 3 DIM period $(P=0.15)$. A difference between treatments was observed in the 4 to 7 DIM period $(P<$ 0.01); when back-transformed, the BHB geometric mean concentrations predicted by the model for this period were $0.66 \mathrm{mmol} / \mathrm{L}(95 \% \mathrm{CI}=0.60,0.73)$ for cows in the INC group and $0.79 \mathrm{mmol} / \mathrm{L}(95 \% \mathrm{CI}=$ $0.72,0.87)$ for cows in the CON group. In other words, cows in the INC group had BHB values 0.83 (95\% CI $=0.77,0.90)$ times those of cows in the CON group. A tendency for a lower natural logarithm of BHB in INC cows was observed for the 8 to 17 DIM period; when back-transformed, BHB geometric mean concentrations predicted by the model for this period were $0.90(95 \%$ $\mathrm{CI}=0.80,1.01) \mathrm{mmol} / \mathrm{L}$ for cows in the INC group and $0.94 \mathrm{mmol} / \mathrm{L}(95 \% \mathrm{CI}=0.84,1.06)$ for cows in the CON group. No significant differences could be observed during the 18 to 26 DIM period.

None of the variables hypothesized to modify the effect of the treatment on blood BHB concentrations demonstrated a significant interaction with milking protocols. When evaluating whether the effect of the treatment on the natural logarithm of blood $\mathrm{BHB}$ varied from one herd to another using the model without and with a random treatment slope, few differences were observed between models assuming a similar treatment effect for all herds and models assuming treatment effects varying by herds. In 1 herd (herd 6), a stronger preventive effect of treatment on blood BHB natural logarithm was observed during the 4 to 7 and 8 to 17 DIM periods. This herd was the only one milking cows 3 times per day.

$\boldsymbol{H} \boldsymbol{Y} \boldsymbol{K}$. Among cows testing positive at least once for HYK between 1 and 26 DIM, 145 were in the CON group and 124 in the INC group. Prevalence of HYK for CON and INC are presented in Figure 3. Estimates of models evaluating the effect of milking protocols on odds of HYK are presented in Table 3. Significant differences between treatment groups were observed during the 4 to $7(P=0.02)$ and 8 to $17 \operatorname{DIM}(P=0.03)$ periods. Odds of HYK for cows in the INC group were $0.40(95 \% \mathrm{CI}=0.18,0.87)$ and $0.65(95 \% \mathrm{CI}=0.43$, 0.96) times those of cows in the CON group during the 4 to 7 and 8 to 17 DIM period, respectively. Predicted probabilities of HYK for each milking protocol are presented in Table 4. During the 4 to 7 DIM period, predicted prevalences of 4.6 and $10.7 \%$ were observed for the INC and CON groups $(P=0.02)$, respectively; these prevalences were, respectively, 13.4 and $19.4 \%$ during the 8 to 17 DIM period $(P=0.03)$.

For the 8 to 17 DIM period, an interaction between parity and treatment was observed $(P=0.04)$. This interaction term is presented in Table 5. During that period, the ratio of odd ratios across parity strata was $2.4(95 \% \mathrm{CI}=1.5-3.7)$, meaning that the estimated effect of the milking protocol was 2.4 times larger in second-parity cows (OR: 2.7) than in cows of third or greater parity (odds ratio $=1.2$ ). The relative excess risk due to interaction was estimated at 0.16 (95\% CI $=-0.92,0.97)$, meaning that the estimated treatment effect on the additive scale in second-parity cows was slightly larger than that of cows in third or greater parity; thus, a positive, but nonsignificant, effect modification was observed when assessed on the additive scale. For this specific DIM period, the predicted prevalence of HYK for a second-parity cow in the CON group was $16 \%(95 \% \mathrm{CI}=0.11,0.24)$ compared with $7 \%(95 \%$ $\mathrm{CI}=0.04,0.11)$ for INC cows. Predicted prevalence of HYK for cows in parity $\geq 3$ were $31 \%(95 \% \mathrm{CI}=0.23$, 0.40) in CON compared with $27 \%$ (95\% CI $=0.20$, 0.36 ) in INC cows.

Body Condition Loss in the Postpartum Period. For $\triangle \mathrm{BCS}$, observations were missing for 104 lactations because one of the BCS values used to calculate this parameter was not collected $(n=101$ lactations) or because cows were culled before the last BCS measurement ( $\mathrm{n}=3$ lactations). A total of 351 


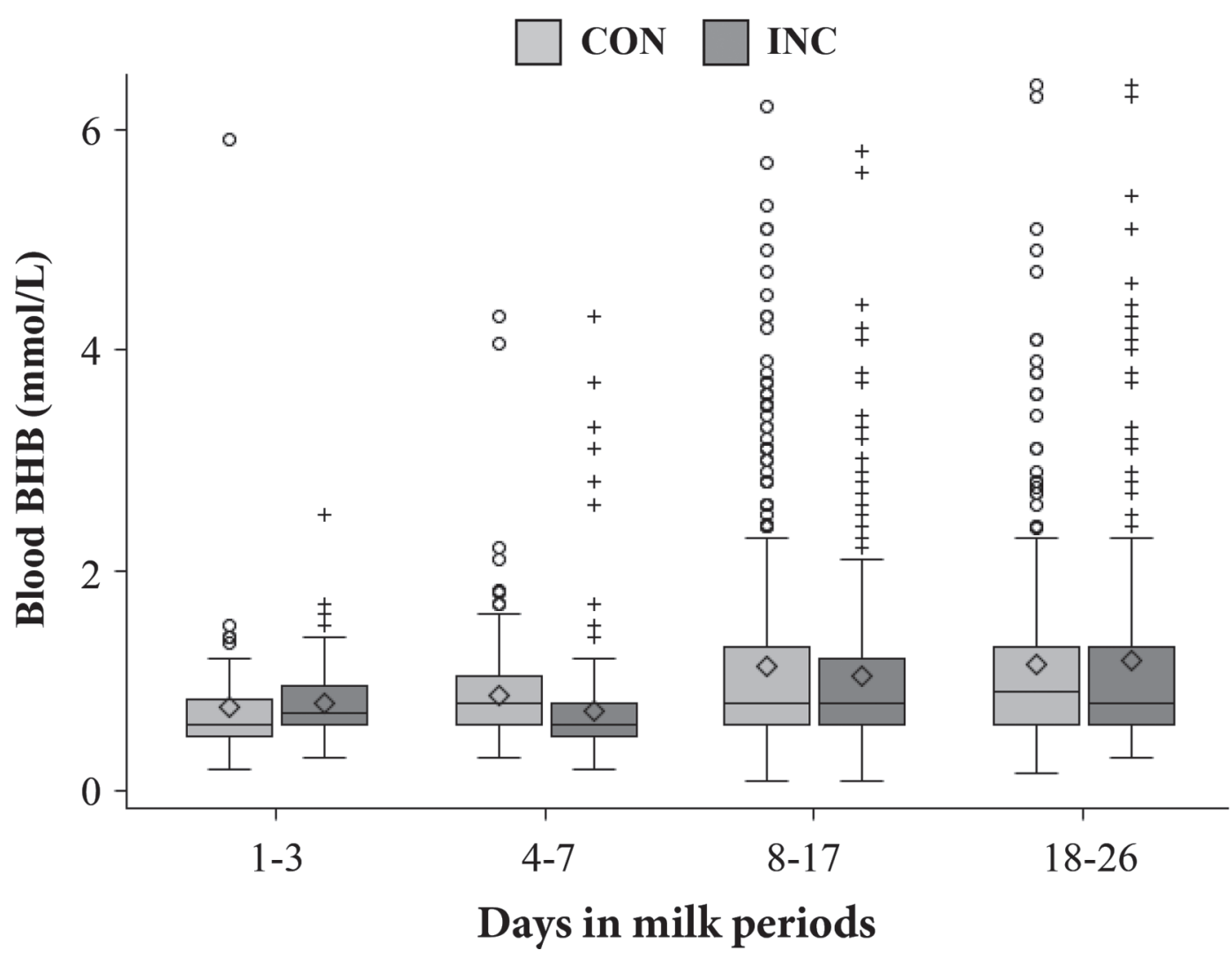

Figure 2. Boxplot of blood BHB concentrations as a function of milking protocols and DIM periods. Data obtained from 813 multiparous Holstein cow lactations from 13 herds participating in a randomized controlled trial evaluating the effect of an incomplete milking protocol (INC) during the first 5 DIM compared with a conventional milking protocol $(\mathrm{CON})$. The sign $(\mathrm{O}$ or +$)$ and line inside the box indicate, respectively, the mean and median milk production. Whiskers are drawn from the box to the most extreme point that is less than or equal to 1.5 times the interquartile range. Observations outside the values delimited by the whiskers are represented by individual markers.

lactations in CON group and 358 lactations in INC group were, therefore, available for analysis of $\triangle \mathrm{BCS}$ in early lactation. Time between BCS assessments ranged from 35 to $78 \mathrm{~d}$. Number of lactations with a $\triangle B C S$ $\geq 0.75$ points was 120 (67 lactations in CON group and 53 in INC group), and 589 had a $\triangle B C S<0.75$ points (284 in CON group and 305 in INC group). Effect of treatment on odds of having a $\triangle B C S \geq 0.75$ points was not significant $(P=0.12)$, whereas odds of $\triangle \mathrm{BCS}$ $\geq 0.75$ points were $0.73(95 \%$ CI: $0.49,1.1)$ times lower for cows following INC compared with those following CON (Table 6).

\section{DISCUSSION}

The objectives of our study were to evaluate, in Holstein dairy herds, the effect of an incomplete milking protocol in early lactation on markers of NEB: ketonemia, HYK, and loss of BCS $\geq 0.75$ points. Previous studies investigating energy output modulation in early lactation by reducing milking frequency or the amount of milk harvested were all conducted on small numbers of cows in research herds (Loiselle et al., 2009; Carbonneau et al., 2012). A larger study was needed to evaluate the relevance of this strategy in commercial settings and to investigate subsequent effects on fertility, control of infectious diseases, culling, and animal welfare. Based on the results of Carbonneau et al. (2012), our initial hypothesis was that the 3 markers of NEB would be improved by the milking strategy used.

For the current study, an RCT design was chosen. This study design is one of the most valid design for demonstrating a causal effect (Dohoo et al., 2009a); however, some potential biases should still be considered. First, farms selected were a convenience sample. Our research protocol required an important investment of time by participating producers and an important change in mentality, which may have led to recruitment of highly innovative and thorough producers. The relatively low prevalence of HYK observed in participating herds, despite the high production level, possibly reflects a better control of the transition period. Nevertheless, a variety of management systems and herd sizes were represented, thus making results 
Table 1. Unconditional estimates ${ }^{1}$ of association between milking protocol and the natural logarithm of blood $\mathrm{BHB}$

\begin{tabular}{|c|c|c|c|c|}
\hline Model and parameter & Estimate & SE & $95 \% \mathrm{CI}$ & $P$-Value \\
\hline \multicolumn{5}{|l|}{ Model 1-3 DIM $(\mathrm{n}=167)$} \\
\hline Intercept & -0.424 & 0.050 & & $<0.01$ \\
\hline \multicolumn{5}{|l|}{ Treatment groups } \\
\hline Conventional milking (CON) & \multicolumn{4}{|c|}{ Referent } \\
\hline Incomplete milking (INC) & 0.100 & 0.069 & $-0.037,0.237$ & 0.15 \\
\hline \multicolumn{5}{|l|}{ Variance } \\
\hline Herd & 0.001 & & & \\
\hline Observation & 0.199 & & & \\
\hline \multicolumn{5}{|l|}{ Model 4-7 DIM ( $\mathrm{n}=430)$} \\
\hline Intercept & -0.232 & 0.048 & & $<0.01$ \\
\hline \multicolumn{5}{|l|}{ Treatment groups } \\
\hline Conventional milking (CON) & & & Referent & \\
\hline Incomplete milking (INC) & -0.185 & 0.042 & $-0.268,-0.102$ & $<0.01$ \\
\hline \multicolumn{5}{|l|}{ Variance } \\
\hline Herd & 0.016 & & & \\
\hline Observation & 0.189 & & & \\
\hline \multicolumn{5}{|l|}{ Model 8-17 DIM $(\mathrm{n}=1,106)$} \\
\hline Intercept & -0.052 & 0.062 & & 0.41 \\
\hline \multicolumn{5}{|l|}{ Treatment groups } \\
\hline Conventional milking (CON) & & & Referent & \\
\hline Incomplete milking (INC) & -0.065 & 0.040 & $-0.143,0.013$ & 0.10 \\
\hline \multicolumn{5}{|l|}{ Variance } \\
\hline Herd & 0.036 & & & \\
\hline Cow & 0.176 & & & \\
\hline Observation & 0.174 & & & \\
\hline \multicolumn{5}{|l|}{ Model 18-27 DIM $(\mathrm{n}=610)$} \\
\hline Intercept & -0.081 & 0.061 & & 0.19 \\
\hline \multicolumn{5}{|l|}{ Treatment groups } \\
\hline Conventional milking (CON) & & & Referent & \\
\hline Incomplete milking (INC) & 0.010 & 0.050 & $-0.087,0.108$ & 0.83 \\
\hline \multicolumn{5}{|l|}{ Variance } \\
\hline Herd & 0.029 & & & \\
\hline Observation & 0.370 & & & \\
\hline
\end{tabular}

${ }^{1}$ Estimates were obtained using 4 linear mixed models using data from 813 multiparous Holstein cow lactations from 13 herds participating in a randomized controlled trial evaluating the effect of an incomplete milking protocol during the first 5 DIM compared with a conventional milking protocol.

generalizable to various production systems. Furthermore, it could be hypothesized that the effect of INC would simply be greater in herds where NEB is less well controlled.

Another potential source of bias is that neither research team nor milking employees could be blinded to cow allocation. Measurement of BHB, however, is a very objective measure and knowing group allocation could hardly influence outcome assessment. On the other hand, BCS assessment is more subjective and its assessment could have been influenced by knowing treatment allocation. Finally, because milking employ-

Table 2. $\beta$-Hydroxybutyrate geometric mean blood concentrations (in mmol/L) and BHB concentration ratio between incompletely and conventionally milked cows ${ }^{1}$

\begin{tabular}{|c|c|c|c|c|c|c|}
\hline \multirow{2}{*}{$\begin{array}{l}\text { DIM } \\
\text { category }\end{array}$} & \multicolumn{4}{|c|}{ Geometric mean (in mmol/L) } & \multicolumn{2}{|c|}{$\mathrm{BHB}_{\text {ratio }^{2}}$} \\
\hline & $\mathrm{CON}$ & $95 \% \mathrm{CI}$ & INC & $95 \% \mathrm{CI}$ & LSM & $95 \% \mathrm{CI}$ \\
\hline$\overline{1-3}$ & 0.65 & $0.59,0.72$ & 0.72 & $0.66,0.80$ & 1.1 & $0.97,1.3$ \\
\hline $4-7$ & 0.79 & $0.72,0.87$ & 0.66 & $0.60,0.73$ & 0.83 & $0.77,0.90^{*}$ \\
\hline $8-17$ & 0.94 & $0.84,1.06$ & 0.90 & $0.80,1.01$ & 0.94 & $0.87,1.0$ \\
\hline $18-27$ & 0.92 & $0.82,1.04$ & 0.93 & $0.83,1.06$ & 1.0 & $0.92,1.1$ \\
\hline
\end{tabular}

${ }^{1}$ Values were computed using LSM estimates obtained from linear mixed models using data from 813 multiparous Holstein cow lactations from 13 herds participating in a randomized controlled trial evaluating the effect of an incomplete milking protocol (INC) during the first 5 DIM compared with a conventional milking protocol $(\mathrm{CON})$

${ }^{2} \mathrm{BHB}$ blood concentrations ratio between intervention and conventional groups (incompletely milked cows:conventionally milk cows).

$* P<0.05$. 


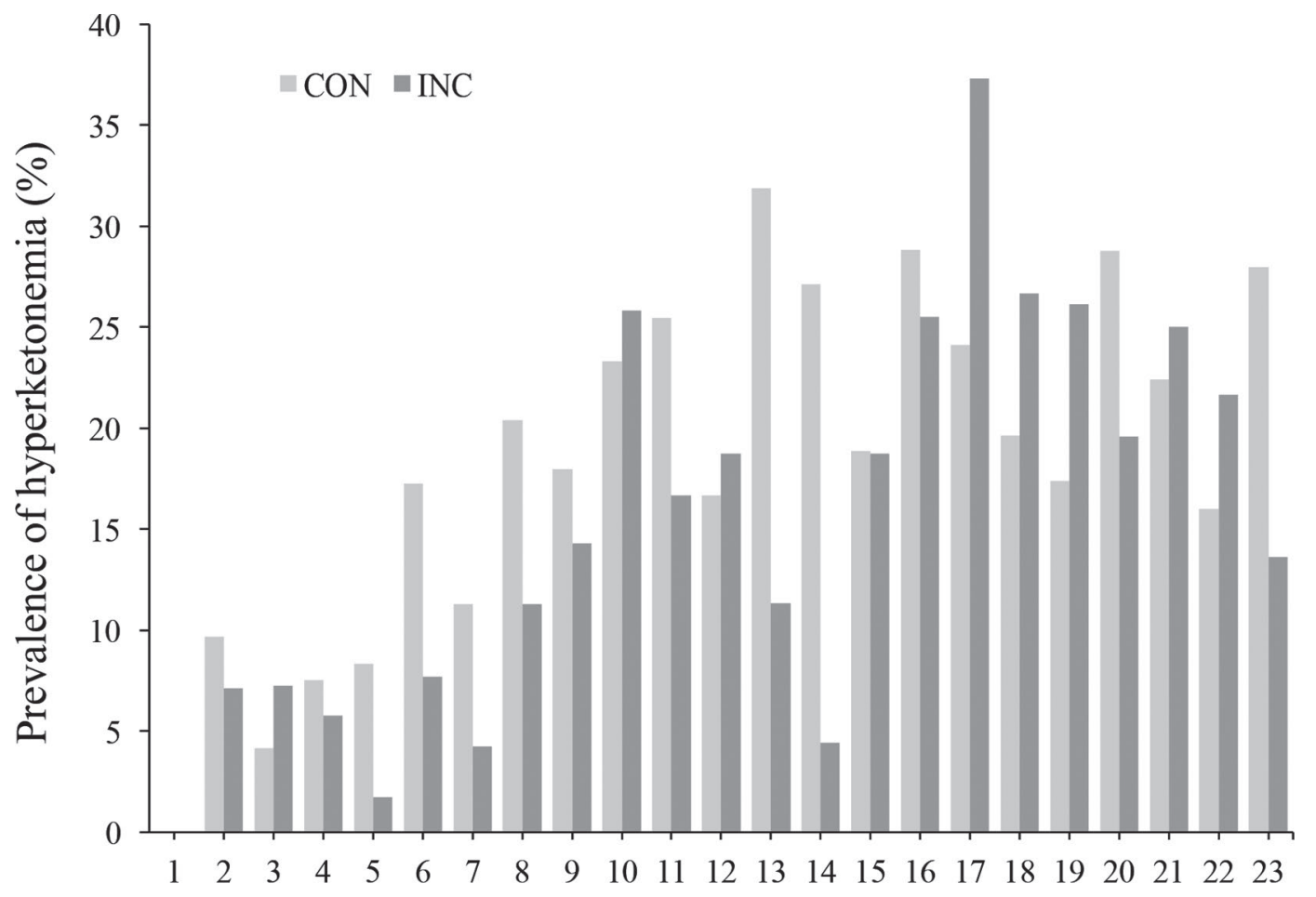

\section{Days in milk}

Figure 3. Histogram of prevalence of hyperketonemia (blood BHB concentration $>1.4 \mathrm{mmol} / \mathrm{L}$ ) as function of milking protocol used. Models estimated using data from 813 multiparous Holstein cow lactations from 13 herds participating in a randomized controlled trial evaluating the effect of an incomplete milking protocol (INC) during the first 5 DIM compared with a conventional milking protocol (CON).

ees were aware of treatment allocation, it is possible that better care was given to cows in the INC group than to cows in the CON group (or the opposite). In the future, a trial conducted using herds with robotic milking solely could be designed to avoid such bias.

In our study, as many producers harvested milk from cows in the INC group using a transparent milking jar to evaluate the amount of milk extracted in real time, the exact amount of milk collected was not automatically recorded by milking system software. Furthermore, many of the computerized milking systems used by participating herds did not record harvested milk when the milking unit was manually stopped before the end of the milking. For this reason, it was impossible to objectively evaluate the compliance of participants when applying the INC protocol. From our discussions with producers involved, and using answers provided by a qualitative end-of-study questionnaire, it appears that many cows in the INC group had higher amount of milk harvested than the established study protocol, especially during the last $2 \mathrm{~d}$ of INC, or were sometimes completely milked by mistake on a given milking. These mistakes, however, are likely to occur if INC is implanted in the future, hence supporting use of intention to treat analysis.

Periods of interest were evaluated in the current study based on milk production physiology, and little difference on ketonemia was expected between treatment groups for the 1 to 3 DIM period. Larger differences in milk production, and consequently on NEB, were expected on $\mathrm{d} 4$ and 5 . Most of the treatment effect on the NEB was, therefore, expected to occur during the 4 to 7 DIM. A short-term and, possibly, a long-term residual effect of treatment was expected during the 8 to 17 and 18 to 26 DIM periods, respectively.

The ketonemia reduction in cows exposed to INC was of small magnitude in the 4 to 7 DIM period. Carbonneau et al. (2012) found a reduction of blood BHB concentrations until 21 DIM for partially milked cows. The milking protocol tested in our study was slightly different than the incomplete milking protocol investigated by Carbonneau et al. (2012). This difference could explain the different effects between studies. When evaluating the effect of INC on the natural logarithm of blood BHB with a random slope at herd level, regression lines from almost all herds were parallel, supposing similar treat- 
Table 3. Unconditional estimates ${ }^{1}$ of association between milking protocol and odds of hyperketonemia (defined as blood BHB $\geq 1.4 \mathrm{mmol} / \mathrm{L}$ )

\begin{tabular}{|c|c|c|c|c|c|}
\hline \multirow[b]{2}{*}{ Model and parameter } & \multicolumn{2}{|c|}{ Estimate } & \multicolumn{2}{|c|}{ Odds ratio $^{2}$} & \multirow[b]{2}{*}{$P$-value } \\
\hline & Mean & $\mathrm{SE}$ & Mean & $95 \% \mathrm{CI}$ & \\
\hline \multicolumn{6}{|l|}{ Model 1-3 DIM $(\mathrm{n}=167)$} \\
\hline Intercept & -2.747 & 0.461 & & & $<0.01$ \\
\hline \multicolumn{6}{|l|}{ Treatment groups } \\
\hline Conventional milking $(\mathrm{CON})$ & \multicolumn{2}{|c|}{ Referent } & \multicolumn{2}{|c|}{ Referent } & \\
\hline Incomplete milking (INC) & 0.182 & 0.262 & 1.20 & $0.35,4.10$ & 0.77 \\
\hline \multicolumn{6}{|l|}{ Variance } \\
\hline Herd & \multicolumn{5}{|l|}{$\mathrm{NE}^{3}$} \\
\hline \multicolumn{6}{|l|}{ Model 4-7 DIM $(\mathrm{n}=430)$} \\
\hline Intercept & -2.124 & 0.353 & & & $<0.01$ \\
\hline \multicolumn{6}{|l|}{ Treatment groups } \\
\hline Conventional milking (CON) & \multicolumn{2}{|c|}{ Referent } & \multicolumn{2}{|c|}{ Referent } & \\
\hline Incomplete milking (INC) & -0.918 & 0.398 & 0.40 & $0.18,0.87$ & 0.02 \\
\hline \multicolumn{6}{|l|}{ Variance } \\
\hline Herd & 0.762 & 0.570 & & & \\
\hline \multicolumn{6}{|l|}{ Model 8-17 DIM $(\mathrm{n}=1,106)$} \\
\hline Intercept & -1.424 & 0.241 & & & $<0.01$ \\
\hline \multicolumn{6}{|l|}{ Treatment groups } \\
\hline Conventional milking $(\mathrm{CON})$ & \multicolumn{2}{|c|}{ Referent } & \multicolumn{2}{|c|}{ Referent } & \\
\hline Incomplete milking (INC) & -0.438 & 0.202 & 0.65 & $0.43,0.96$ & 0.03 \\
\hline \multicolumn{6}{|l|}{ Variance } \\
\hline Herd & 0.300 & 0.186 & & & \\
\hline \multirow{2}{*}{\multicolumn{6}{|c|}{ Model 18-27 DIM $(\mathrm{n}=610)$}} \\
\hline & & & & & \\
\hline Intercept & -1.306 & & & & $<0.01$ \\
\hline \multicolumn{6}{|l|}{ Treatment groups } \\
\hline Conventional milking (CON) & \multicolumn{2}{|c|}{ Referent } & \multicolumn{2}{|c|}{ Referent } & \\
\hline Incomplete milking (INC) & 0.095 & 0.197 & 1.10 & $1.75,1.60$ & 0.63 \\
\hline \multicolumn{6}{|l|}{ Variance } \\
\hline Herd & 0.194 & 0.101 & & & \\
\hline
\end{tabular}

${ }^{1}$ Estimates were obtained using generalized linear mixed models, using a logit link and data from 813 multiparous Holstein cow lactations from 13 herds participating in a randomized controlled trial evaluating the effect of an incomplete milking protocol during the first 5 DIM compared with a conventional milking protocol ${ }^{2}$ Odds ratio comparing odds of hyperketonemia in cows milked incompletely compared with cows milked conventionally.

${ }^{3} \mathrm{NE}=$ not estimated.

Table 4. Predicted probability ${ }^{1}$ of hyperketonemia in incompletely and conventionally milked cows

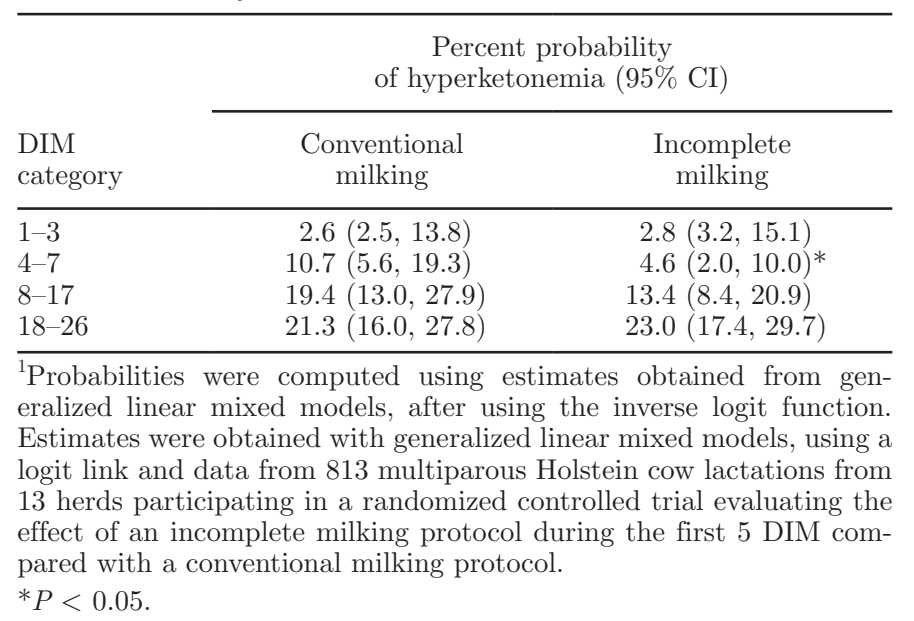

ment effects. In one herd, the only one milking fresh cows 3 times per day, a more important effect of the INC could be observed. Increasing milking frequency in early lactation increases milk production (Bar-Peled et al., 1995; Hale et al., 2003; Wall et al., 2006) and has been reported to accentuate NEB (Andersen et al., 2004). We could hypothesize that cows milked 3 times per day could possibly benefit more from the INC than cows milked twice a day; this hypothesis will have to be validated in future studies. None of the other putative effect modifiers hypothesized to modify the effect of the treatment on the natural logarithm of blood BHB concentrations demonstrated significant interaction with milking protocols. Because sample size of the RCT was computed to demonstrate differences between treatments on odds of HYK, the power of the study was not sufficient to further expose difference of treatment effect across levels of effect modifier. Furthermore, for some effect modifiers (e.g., dystocia), very few events were recorded, and results regarding absence of effect 
Table 5. Effect of an incomplete milking protocol on odds of hyperketonemia (defined as blood BHB $\geq 1.4 \mathrm{mmol} / \mathrm{L}$ ) stratified by parity level during the 8 to 17 DIM period

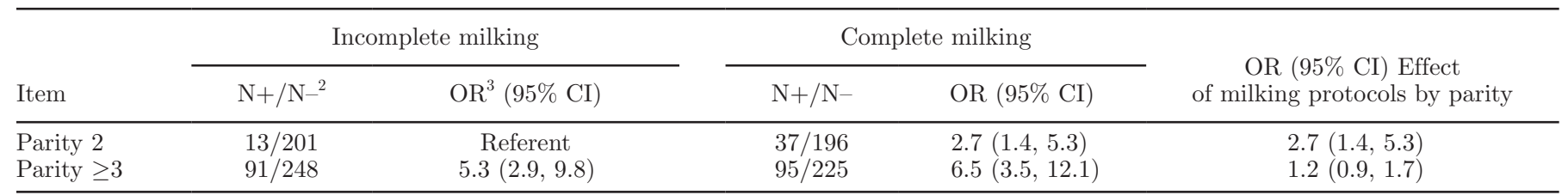

${ }^{1}$ Values were obtained using a generalized linear mixed model, using a logit link and data from 813 multiparous Holstein cow lactations from 13 herds participating in a randomized controlled trial evaluating the effect of an incomplete milking protocol during the first 5 DIM compared with a conventional milking protocol. During the 8 to 17 DIM period, 333 cows had 2 observations available for analysis, whereas only 1 observation was available for 462 cows. Measure of effect modification on the multiplicative scale: OR (95\% CI): 2.4 (1.5, 3.7). Measure of effect modification on the additive scale: Relative excess risk due to interaction $(95 \% \mathrm{CI})$ : $0.16(-0.92,0.97)$.

${ }^{2}$ Number of observations positive $(\mathrm{N}+)$ and negative $(\mathrm{N}-)$ for hyperketonemia.

${ }^{3}$ Odds ratio adjusted for herd effect.

modification should be interpreted cautiously. In the future, if this milking strategy is implemented by dairy producers, larger observational studies could be conducted to identify types of cows (or herds) that could benefit from this management strategy.

The incomplete milking protocol was effective for reducing the HYK prevalence. Consequences of HYK are numerous. A blood BHB concentration $\geq 1.4 \mathrm{mmol} / \mathrm{L}$ was associated with a daily milk yield reduction of $6.9 \%$ during the first month of lactation (Chapinal et al., 2012; McArt et al., 2012). Ospina et al. (2010) and McArt et al. (2012) reported that HYK cows had 6.9 times greater odds of experiencing a displaced abomasum. Duffield et al. (2009) reported 3.4 times higher odds of metritis in HYK cows than in normoketonemic cows. Finally, cows with HYK were 4.5 times more likely to be removed from the herd during the first 30 DIM (McArt et al., 2012). Additional analyses will, however, be needed to determine whether the INC will lead to additional positive effects on these subsequent health events. Nevertheless, the observed reduction in HYK prevalence is encouraging, especially because HYK could be controlled during the first 17 DIM, a period of critical importance. Indeed, McArt et al. (2012) observed that cows first testing positive to HYK between 3 to 7 DIM were 4.5 (95\% CI $=1.7$,

Table 6. Unconditional estimates ${ }^{1}$ of association between milking protocol and odds of losing $\geq 0.75$ point of body condition during the first $7 \mathrm{wk}$ of lactation

\begin{tabular}{|c|c|c|c|c|c|}
\hline \multirow[b]{2}{*}{ Model and parameter } & \multicolumn{2}{|c|}{ Estimate } & \multicolumn{2}{|c|}{ Odds ratio ${ }^{2}$} & \multirow[b]{2}{*}{$P$-value } \\
\hline & Mean & $\mathrm{SE}$ & Mean & $95 \% \mathrm{CI}$ & \\
\hline Intercept & -1.562 & 0.129 & & & $<0.01$ \\
\hline Treatment groups & & & & & 0.12 \\
\hline Conventional milking $(\mathrm{CON})$ & & \multicolumn{3}{|c|}{ Referent } & \\
\hline Incomplete milking (INC) & -0.157 & 0.102 & 0.73 & $0.49,1.1$ & \\
\hline Herd & & & & & $<0.79$ \\
\hline 1 & -0.079 & 0.250 & 0.44 & $0.11,1.8$ & \\
\hline 2 & -0.493 & 0.392 & 0.29 & $0.06,1.4$ & \\
\hline 3 & -0.137 & 0.378 & 0.42 & $0.09,2.0$ & \\
\hline 4 & -0.232 & 0.306 & 0.39 & $0.09,1.7$ & \\
\hline 5 & 0.163 & 0.324 & 0.56 & $0.13,2.5$ & \\
\hline 6 & -0.793 & 0.693 & 0.22 & $0.03,1.6$ & \\
\hline 7 & 0.440 & 0.313 & 0.74 & $0.17,3.3$ & \\
\hline 8 & 0.259 & 0.535 & 0.62 & $0.11,3.6$ & \\
\hline 9 & 0.040 & 0.310 & 0.50 & $0.11,2.2$ & \\
\hline 10 & -0.238 & 0.514 & 0.38 & $0.67,2.1$ & \\
\hline 11 & -0.077 & 0.298 & 0.44 & $0.10,1.9$ & \\
\hline 12 & 0.405 & 0.543 & 0.71 & $0.12,4.2$ & \\
\hline 13 & & \multicolumn{4}{|c|}{ Referent } \\
\hline
\end{tabular}

${ }^{1}$ Estimates were obtained using a logistic model. Data from 709 multiparous Holstein cow's lactations from 13 herds participating to a randomized controlled trial evaluating the effect of an incomplete milking protocol during the first 5 DIM compared with a conventional milking protocol.

${ }^{2}$ Odds ratio comparing odds of hyperketonemia in cows milked incompletely compared with cows milked conventionally. 
11.7) times more likely to be removed from the herd, $6.1(95 \% \mathrm{CI}=2.3,16.0)$ times more likely to develop a displaced abomasum, 0.7 (95\% CI $=0.6$ to 0.8 ) times as likely to conceive on first service, and produced 2.2 $\mathrm{kg}$ less milk per day for the first 30 DIM than cows testing positive at $8 \mathrm{DIM}$ or later.

Regarding effect modification by parity during the 8 to 17 DIM period, second parity seemed to benefit more from the INC treatment than older cows. We hypothesized that second-parity cows are still partitioning energy for growing, and that limiting energy output would, therefore, be even more important for these cows. The higher prevalence of HYK for cows in third or greater parity in our study is in accordance with values obtained by Santschi et al. (2016) and Tatone et al. (2017).

No significant effect of milking protocols on fat mobilization in the early lactation period was observed despite the lower odds of $\triangle \mathrm{BCS} \geq 0.75$ points in the INC group. Literature is unclear when trying to link BCS to metabolic disorders (Ruegg et Milton, 1995; Rasmussen, 1999); one possible reason for this is the imprecision associated with $\triangle \mathrm{BCS}$, potentially leading to type II error (Morin et al., 2017).

The effects of the INC protocol on subsequent milk yield and composition, incidence of postpartum diseases, reproductive performances, and culling will have to be analyzed before this procedure can be recommended on dairies. Results on the effect of an incomplete milking on animal behaviors have been published by Krug et al. (2017), and these results suggested that an incomplete milking had very little effect on cow behaviors, and thus possibly caused little discomfort. If no negative effects of the INC protocol on milk production and composition exist, we could imagine the implementation of this protocol in commercial dairies, particularly those using robotic milking systems where it could be automatized. Furthermore, incomplete milking of dairy cows in the early lactation is a very natural approach that is more respectful of the cows' physiology and that can be applied at very low costs. It also has the potential to be very well received by the general public and by consumers, who express increasing desire to buy products produced in a more natural fashion, while answering dairy producers' needs for productivity.

\section{CONCLUSIONS}

The investigated treatment was an effective way to reduce the severity of NEB during early postpartum period. More specifically, it reduced ketonemia during the 4 to 7 DIM period and odds of HYK during the 4 to 7 and 8 to 17 DIM periods.

\section{ACKNOWLEDGMENTS}

This project was funded by Novalait Inc., Fonds de recherche du Québec - Nature et technologies (FRQNT, Québec City, QC, Canada), and Ministère de l'Agriculture, des Pêcheries et de l'Alimentation du Québec (MAPAQ, Québec City, QC, Canada). Caroline Bergeron, Josée Lemay-Courchesne, and Jean-Philippe Pelletier (Université de Montréal, St-Hyacinthe, QC) are also acknowledged for their technical help, as well as dairy farmers for their willingness to participate in the study. No conflict of interest was declared for this paper.

\section{REFERENCES}

Andersen, J. B., N. C. Friggens, T. Larsen, M. Vestergaard, and K. L. Ingvartsen. 2004. Effect of energy density in the diet and milking frequency on plasma metabolites and hormones in early lactation dairy cows. J. Vet. Med. A Physiol. Pathol. Clin. Med. 51:52-57. https://doi.org/10.1111/j.1439-0442.2004.00605.x.

Bar-Peled, U., E. Maltz, I. Bruckental, Y. Folman, Y. Kali, H. Gacitua, A. R. Lehrer, C. H. Knight, B. Robinzon, H. Voet, and H. Tagari. 1995. Relationship between frequent milking or suckling in early lactation and milk production of high producing dairy cows. J. Dairy Sci. 78:2726-2736.

Bauman, D. E., and W. B. Currie. 1980. Partitioning of nutrients during pregnancy and lactation: A review of mechanisms involving homeostasis and homeorhesis. J. Dairy Sci. 63:1514-1529.

Carbonneau, E., A. M. de Passille, J. Rushen, B. G. Talbot, and P. Lacasse. 2012. The effect of incomplete milking or nursing on milk production, blood metabolites, and immune functions of dairy cows. J. Dairy Sci. 95:6503-6512. https://doi.org/10.3168/jds.2012 -5643 .

Chapinal, N., M. Carson, T. F. Duffield, M. Capel, S. Godden, M. Overton, J. E. Santos, and S. J. LeBlanc. 2011. The association of serum metabolites with clinical disease during the transition period. J. Dairy Sci. 94:4897-4903. https://doi.org/10.3168/jds .2010-4075.

Chapinal, N., M. E. Carson, S. J. LeBlanc, K. E. Leslie, S. Godden, M. Capel, J. E. Santos, M. W. Overton, and T. F. Duffield. 2012. The association of serum metabolites in the transition period with milk production and early-lactation reproductive performance. J. Dairy Sci. 95:1301-1309. https://doi.org/10.3168/jds.2011-4724.

Cook, R. D., and S. Weisberg. 1982. Residuals and Influence in Regression. Chapman and Hall, New York, NY.

Djemali, M., A. E. Freeman, and P. J. Berger. 1987. Reporting of dystocia scores and effects of dystocia on production, days open, and days dry from dairy herd improvement data. J. Dairy Sci. 70:21272131. https://doi.org/10.3168/jds.S0022-0302(87)80263-1.

Dohoo, I. R., S. W. Martin, and H. Stryhn. 2009a. Introduction to observational studies. Pages 139-146 in Veterinary Epidemiologic Research. 2nd ed. VER Inc., Charlottetown, PEI, Canada.

Dohoo, I. R., S. W. Martin, and H. Stryhn. 2009b. Linear regression. Pages 323-360 in Veterinary Epidemiologic Research. 2nd ed. VER Inc., Charlottetown, PEI, Canada.

Dohoo, I. R., S. W. Martin, and H. Stryhn. 2009c. Mixed models for continuous data. Pages 553-565 in Veterinary Epidemiologic Research. 2nd ed. VER Inc., Charlottetown, PEI, Canada.

Dohoo, I. R., S. W. Martin, and H. Stryhn. 2009d. Model-building strategies. Pages 365-390 in Veterinary Epidemiologic Research. 2nd ed. VER Inc., Charlottetown, PEI, Canada.

Dubuc, J., and J. Denis-Robichaud. 2017. A dairy herd-level study of postpartum diseases and their association with reproductive performance and culling. J. Dairy Sci. 100:3068-3078. https://doi .org/10.3168/jds.2016-12144. 
Duffield, T. F., K. D. Lissemore, B. W. McBride, and K. E. Leslie. 2009. Impact of hyperketonemia in early lactation dairy cows on health and production. J. Dairy Sci. 92:571-580. https://doi.org/ 10.3168/jds.2008-1507.

Ferguson, J. D., D. T. Galligan, and N. Thomsen. 1994. Principal descriptors of body condition score in Holstein cows. J. Dairy Sci. 77:2695-2703. https://doi.org/10.3168/jds.S0022-0302(94)77212 $-\mathrm{X}$.

Fisher, R. A. 1935. The logic of inductive inference. J. R. Stat. Soc. 98:39-82

Geishauser, T., K. Leslie, J. Tenhag, and A. Bashiri. 2000. Evaluation of eight cow-side ketone tests in milk for detection of subclinical ketosis in dairy cows. J. Dairy Sci. 83:296-299. https://doi.org/10 .3168/jds.S0022-0302(00)74877-6.

Gohary, K., M. W. Overton, M. Von Massow, S. J. LeBlanc, K. D. Lissemore, and T. F. Duffield. 2016. The cost of a case of subclinical ketosis in Canadian dairy herds. Can. Vet. J. 57:728-732.

Hale, S. A., A. V. Capuco, and R. A. Erdman. 2003. Milk yield and mammary growth effects due to increased milking frequency during early lactation. J. Dairy Sci. 86:2061-2071. https://doi.org/10 .3168/jds.S0022-0302(03)73795-3.

Herdt, T. H. 2000. Ruminant adaptation to negative energy balance. Influences on the etiology of ketosis and fatty liver. Vet. Clin. North Am. Food Anim. Pract. 16:215-230.

Hollis, S., and F. Campbell. 1999. What is meant by intention to treat analysis? Survey of published randomised controlled trials. BMJ 319:670-674.

Holtenius, P., and K. Holtenius. 1996. New aspects of ketone bodies in energy metabolism of dairy cows: a review. Zentralbl. Veterinarmed. A 43:579-587.

Horst, R. L., J. P. Goff, T. A. Reinhardt, and D. R. Buxton. 1997. Strategies for preventing milk fever in dairy cattle. J. Dairy Sci 80:1269-1280. https://doi.org/10.3168/jds.S0022-0302(97)76056 $-9$.

Iwersen, M., U. Falkenberg, R. Voigtsberger, D. Forderung, and W. Heuwieser. 2009. Evaluation of an electronic cowside test to detect subclinical ketosis in dairy cows. J. Dairy Sci. 92:2618-2624. https://doi.org/10.3168/jds.2008-1795.

Keown, J. F., R. W. Everett, N. B. Empet, and L. H. Wadell. 1986. Lactation curves. J. Dairy Sci. 69:769-781.

Knol, M. J., I. van der Tweel, D. E. Grobbee, M. E. Numans, and M. I. Geerlings. 2007. Estimating interaction on an additive scale between continuous determinants in a logistic regression model. Int. J. Epidemiol. 36:1111-1118. https://doi.org/10.1093/ije/dym157.

Knol, M. J., and T. J. VanderWeele. 2012. Recommendations for presenting analyses of effect modification and interaction. Int. J. Epidemiol. 41:514-520. https://doi.org/10.1093/ije/dyr218.

Krug, C., T. J. DeVries, J. P. Roy, J. Dubuc, and S. Dufour. 2017. Incomplete milking in early lactation does not affect dairy cows resting behaviors: Results from a randomized controlled trial. Front. Vet. Sci. 4: https://doi.org/10.3389/fvets.2017.00066.

Loiselle, M. C., C. Ster, B. G. Talbot, X. Zhao, G. F. Wagner, Y. R. Boisclair, and P. Lacasse. 2009. Impact of postpartum milking frequency on the immune system and the blood metabolite concentration of dairy cows. J. Dairy Sci. 92:1900-1912. https://doi.org/ 10.3168/jds.2008-1399.

McArt, J. A., D. V. Nydam, and G. R. Oetzel. 2012. Epidemiology of subclinical ketosis in early lactation dairy cattle. J. Dairy Sci. 95:5056-5066. https://doi.org/10.3168/jds.2012-5443.

McArt, J. A., D. V. Nydam, and M. W. Overton. 2015. Hyperketonemia in early lactation dairy cattle: A deterministic estimate of component and total cost per case. J. Dairy Sci. 98:2043-2054. https://doi.org/10.3168/jds.2014-8740.

Morin, P. A., Y. Chorfi, J. Dubuc, J. P. Roy, D. Santschi, and S. Dufour. 2017. Short communication: An observational study investigating inter-observer agreement for variation over time of body condition score in dairy cows. J. Dairy Sci. 100:3086-3090. https://doi.org/10.3168/jds.2016-11872.
NRC. 2001. Nutrient Requirements of Dairy Cattle. 7th ed. Natl Acad. Press, Washington, DC.

O'Connor, A. M., J. M. Sargeant, I. A. Gardner, J. S. Dickson, M. E. Torrence, C. E. Dewey, I. R. Dohoo, R. B. Evans, J. T. Gray, M. Greiner, G. Keefe, S. L. Lefebvre, P. S. Morley, A. Ramirez, W. Sischo, D. R. Smith, K. Snedeker, J. Sofos, M. P. Ward, R. Wills, and C. Steering. 2010. The REFLECT statement: methods and processes of creating reporting guidelines for randomized controlled trials for livestock and food safety. J. Vet. Intern. Med. 24:57-64. https://doi.org/10.1111/j.1939-1676.2009.0441.x.

Ospina, P. A., D. V. Nydam, T. Stokol, and T. R. Overton. 2010. Evaluation of nonesterified fatty acids and beta-hydroxybutyrate in transition dairy cattle in the northeastern United States: Critical thresholds for prediction of clinical diseases. J. Dairy Sci. 93:546-554. https://doi.org/10.3168/jds.2009-2277.

Pedron, O., F. Cheli, E. Senatore, D. Baroli, and R. Rizzi. 1993. Effect of body condition score at calving on performance, some blood parameters, and milk fatty acid composition in dairy cows. J. Dairy Sci. 76:2528-2535. https://doi.org/10.3168/jds.S0022 $-0302(93) 77588-8$

Raboisson, D., M. Mounie, E. Khenifar, and E. Maigne. 2015. The economic impact of subclinical ketosis at the farm level: Tackling the challenge of over-estimation due to multiple interactions. Prev. Vet. Med. 122:417-425. https://doi.org/10.1016/j.prevetmed.2015 .07 .010 .

Rasmussen, L. K., B. L. Nielsen, J. E. Pryce, T. T. Mottram, and R. F. Veerkamp. 1999. Risk factors associated with the incidence of ketosis in dairy cows. Anim. Sci. 68:8.

Ruegg, P. L., and R. L. Milton. 1995. Body condition scores of Holstein cows on Prince Edward Island, Canada: Relationships with yield, reproductive performance, and disease. J. Dairy Sci. 78:552-564. https://doi.org/10.3168/jds.S0022-0302(95)76666-8.

Santschi, D. E., R. Lacroix, J. Durocher, M. Duplessis, R. K. Moore, and D. M. Lefebvre. 2016. Prevalence of elevated milk beta-hydroxybutyrate concentrations in Holstein cows measured by Fourier-transform infrared analysis in Dairy Herd Improvement milk samples and association with milk yield and components. J. Dairy Sci. 99:9263-9270. https://doi.org/10.3168/jds.2016-11128.

Stevenson, J. S., and E. P. Call. 1988. Reproductive disorders in the periparturient dairy cow. J. Dairy Sci. 71:2572-2583. https://doi .org/10.3168/jds.S0022-0302(88)79846-X.

Suthar, V. S., J. Canelas-Raposo, A. Deniz, and W. Heuwieser. 2013 Prevalence of subclinical ketosis and relationships with postpartum diseases in European dairy cows. J. Dairy Sci. 96:2925-2938. https://doi.org/10.3168/jds.2012-6035.

Tamminga, S., P. A. Luteijn, and R. G. M. Meijer. 1997. Changes in composition and energy content of liveweight loss in daily cows with time after parturition. Livest. Prod. Sci. 52:31-38. https:// doi.org/10.1016/S0301-6226(97)00115-2.

Tatone, E. H., T. F. Duffield, S. J. LeBlanc, T. J. DeVries, and J. L. Gordon. 2017. Investigating the within-herd prevalence and risk factors for ketosis in dairy cattle in Ontario as diagnosed by the test-day concentration of beta-hydroxybutyrate in milk. J. Dairy Sci. 100:1308-1318. https://doi.org/10.3168/jds.2016-11453.

Wall, E. H., H. M. Crawford, S. E. Ellis, G. E. Dahl, and T. B. McFadden. 2006. Mammary response to exogenous prolactin or frequent milking during early lactation in dairy cows. J. Dairy Sci. 89:46404648. https://doi.org/10.3168/jds.S0022-0302(06)72514-0.

Wang, X., X. Li, C. Zhao, P. Hu, H. Chen, Z. Liu, G. Liu, and Z. Wang. 2012. Correlation between composition of the bacterial community and concentration of volatile fatty acids in the rumen during the transition period and ketosis in dairy cows. Appl. Environ. Microbiol. 78:2386-2392.

Wildman, E. E., G. M. Jones, P. E. Wagner, R. L. Boman, H. F. Trout, and T. N. Lesch. 1982. A dairy cow body condition scoring system and its relationship to selected production characteristics. J. Dairy Sci. 65:495-497. 